\title{
Evaluation of Sintering Behavior of Premix Al-Zn-Mg-Cu Alloy Powder
}

\author{
Haris Rudianto, ${ }^{1}$ Gwang Joo Jang, ${ }^{2}$ Sang Sun Yang, ${ }^{2}$ Yong Jin Kim, ${ }^{2}$ and Ivo Dlouhy ${ }^{1}$ \\ ${ }^{1}$ Institute of Materials Science and Engineering, NETME Centre, Brno University of Technology, Technicka 2896/2, \\ 61669 Brno, Czech Republic \\ ${ }^{2}$ Powder Technology Research Group, Korea Institute of Materials Science, 797 Changwondaero, Changwon, \\ Gyeongsangnam-do 642-831, Republic of Korea \\ Correspondence should be addressed to Haris Rudianto; rudianto@fme.vutbr.cz
}

Received 15 December 2014; Revised 12 March 2015; Accepted 13 March 2015

Academic Editor: Jiangbo Sha

Copyright (C) 2015 Haris Rudianto et al. This is an open access article distributed under the Creative Commons Attribution License, which permits unrestricted use, distribution, and reproduction in any medium, provided the original work is properly cited.

Sintering of light aluminium alloys powder has been investigated as a way to substitute steels in automotive and aerospace industries. Premix Al-5.5Zn-2.5Mg-0.5Cu composite powder called Alumix 431D was analyzed in this research. Sintering was carried out under ultra high purity nitrogen gas and before reaching sintering temperature, green samples were delubricated at $400^{\circ} \mathrm{C}$ for $30 \mathrm{~min}$. The powder possesses high sinterability by reaching $96 \%$ relative density at $580^{\circ} \mathrm{C}$ sintering temperature. Formation of liquid phase seems to support achieving high sintering density. Optimum mechanical properties also were obtained under those conditions. T6 heat treatment was done to improve the mechanical properties by formation of precipitation strengthening, and $\mathrm{MgZn} \mathrm{n}_{2}$ appears to be dominant strengthening precipitate. X-ray diffraction, optical microscopy, and SEM-EDS were used to characterize powder, and sintered and heat treated samples.

\section{Introduction}

Sintering technology of aluminium powder has been considered to be a low cost manufacturing process for automotive parts. With rising price of oil, this can be alternative for industry to produce low cost and light weight parts and other light weight applications $[1,2]$. Thanks to their attractive mechanical properties the lower density aluminium alloys and their composites prepared by powder metallurgy route appear to be important candidate materials for applications and sinterability conditions of aluminium composites powder.

From all possible parameters compaction pressure has important role in affecting the matrix composite density besides the sintering temperature. Optimum compaction pressure can support powder to reach optimum sintering density. Variable pressure will greatly influence the green density. There are advantages and disadvantages by using low and high compaction pressure. No surface machining after sintering is desirable and expected from high compaction pressure. However at low compaction pressure, the cost of power needed is also low and safe for wearability of mold [3].

Sintering of aluminium powder has difficulty to wet with another particle due to its oxide layer, $\mathrm{Al}_{2} \mathrm{O}_{3}$. The thickness of this oxide layer can be up to $100 \mathrm{~nm}$. High melting point of $\mathrm{Al}_{2} \mathrm{O}_{3}$ hinders diffusivity of aluminium during sintering. Magnesium is considered to be an agent to remove oxide layer due to its reactive behavior at lower temperature to form spinel, $\mathrm{MgAl}_{2} \mathrm{O}_{4}$. Sintering atmosphere is as well important factor to gain high densification. Nitrogen gas is considered to be suitable atmosphere for sintering of aluminium powder, because nitrogen gas is able to increase diffusivity during sintering of aluminium by liquid phase formation $[4,5]$.

AA7XXX alloys, which contain $\mathrm{Zn}, \mathrm{Mg}$, and $\mathrm{Cu}$, have been proved to have high mechanical properties by utilizing their heat treatable properties. Ratio of $\mathrm{Zn}$ and $\mathrm{Mg}$ in this alloy is important for formation of strengthening precipitate $\mathrm{MgZn}_{2}$. Ready to press Alumix 431D which has chemical composition of $\mathrm{Al}-5.5 \mathrm{Zn}-2.5 \mathrm{Mg}-0.5 \mathrm{Cu}$ was investigated in this research. This powder is a new version of Alumix 431, 


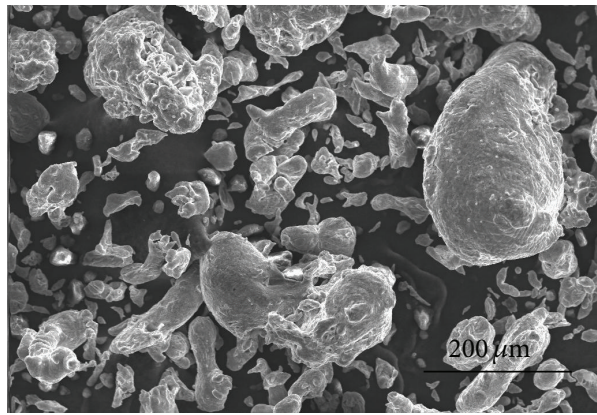

(a)

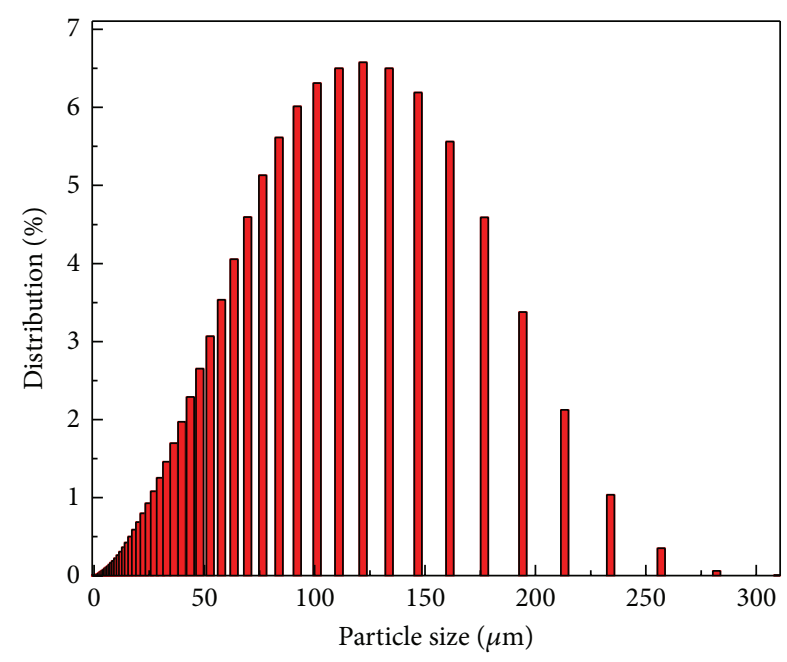

(b)

Figure 1: (a) Particle morphology and (b) particle size distribution of Alumix 431D powder.

which has similar chemical compositions. Some researchers did investigation on Alumix 431 with lower compaction pressure, and Martín and Castro did so with compaction pressure of $400 \mathrm{MPa}$ [4]. Although with this pressure, it gave acceptable sintering density, there will be huge shrinkage especially on surface, so finishing work after sintering is necessary. So, the purpose as well as aim of this research is to investigate sinterability of the improved chemical compositions of Alumix 431D with high compaction pressure.

\section{Materials and Experiments}

In this research, Alumix 431D was analyzed which has chemical compositions of Al-5.5Zn-2.5Mg-0.5Cu with $1.5 \mathrm{wt} \%$ of lubricant. The powder was supplied by Ecka Granules, Germany. This powder has theoretical density of $2.79 \mathrm{~g} / \mathrm{cm}^{3}$. Dry method particle size analyzer was used to estimate particle size distribution of this powder. DSC-TGA was carried out to investigate thermal behavior of this powder and carried out under ultra high purity nitrogen gas (99.9999\%) up to $800^{\circ} \mathrm{C}$. X-ray diffraction (XRD) was used to determine phase compositions in particular to identify precipitates after sintering and T6 heat treatment, and the diffraction pattern was obtained by Rigaku Diffractometer with $\mathrm{Cu} K \alpha$ radiation $(\lambda=0.154 \mathrm{~nm})$ in the range of $20-100^{\circ}$ by the step and scanning speed of $0.02^{\circ}$ and $5^{\circ} / \mathrm{min}$. Microstructure was observed by scanning electron microscopy (SEM) along with energy dispersive X-ray spectroscopy (EDS) from Carl Zeiss Ultra Plus and Oxford Instruments X-MAX, respectively.

Powder was compacted with dual action press at $700 \mathrm{MPa}$. Green density was measured by dividing mass by volume. Sintering was under ultra high purity nitrogen gas for 99.9999\% and before reaching the sintering temperature, compacted samples were delubricated at $400^{\circ} \mathrm{C}$ for $30 \mathrm{~min}$. Sintering density was obtained by using Archimedes method.

Hardness test and tensile test were carried out to investigate mechanical properties. Rockwell hardness was performed to measure hardness of the sintered and heat treated materials, and the hardness was measured with Rockwell B hardness scale with $100 \mathrm{kgf}$ and 1/16 in diameter of diamond ball indenter. Instron instrument was used to carry out tensile test with crosshead speed of $1 \mathrm{~mm} / \mathrm{min}$. Tensile test specimen was made according to ASTM E8 standard with $25 \mathrm{~mm}$ gauge length, $6 \mathrm{~mm}$ width, and $3 \mathrm{~mm}$ thickness. To optimize mechanical properties relating to microstructure of the sample, T6 heat treatment was applied. Sintered samples were heated until reaching solid solution condition at $520^{\circ} \mathrm{C}$ and followed by water quenching and artificial aging for 24 hours at $173^{\circ} \mathrm{C}$. Dispersion strengthening by precipitates was expected after T6 heat treatment.

\section{Results and Discussion}

3.1. Powder Characterization. Powder was characterized to identify its morphology as shown by Figure 1(a). The figure shows irregular shape of powder which is commonly expected from powder made by gas atomization process. Irregular shape of powder tends to have better compactability due to its shape which is able to fill spaces between each particle during compaction compared to circular shape. And another powder characterization is particle size distribution measurement. Dry method was carried out to measure average particle size for this powder, particle size distribution graph as shown in Figure 1(b), and average size of this powder is $105.3 \mu \mathrm{m}$. Particle size distribution is one of powder characteristics which strongly affect the sinterability of this material. Effect of particles size on sintering behaviour of aluminium powder was investigated by Liu et al. From their research outcomes, aluminium alloys powder with $\sim 100 \mu \mathrm{m}$ particle size has been found to supply optimum sintering density [5].

Determination of thermal properties of this powder is important to estimate its sintering temperature and delubricating temperature. Figure 2 shows DSC-TGA curves of 


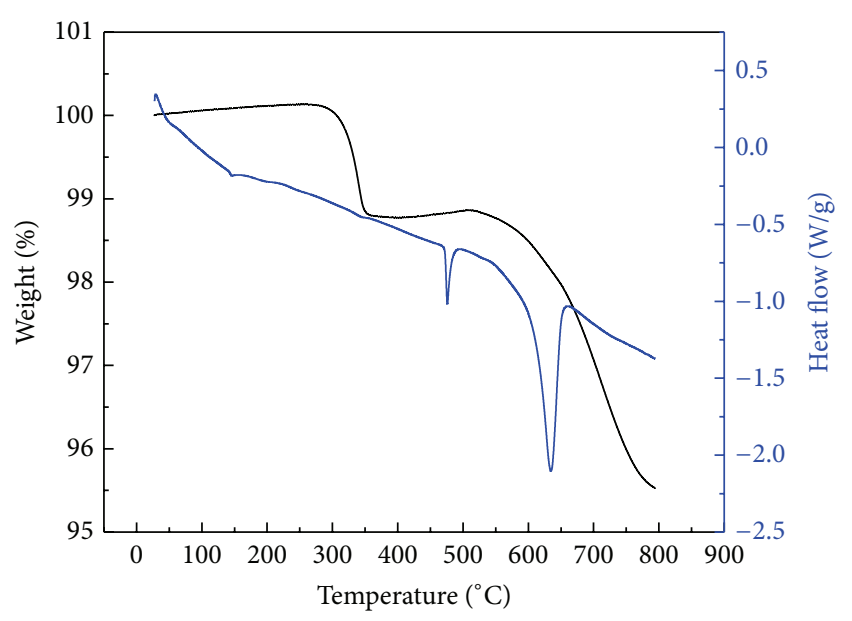

Figure 2: DSC-TGA graph of Alumix 431D powder.

Alumix 431D. As it is obvious from DSC graph (blue line), this powder has two endothermic peaks. The first one at $450^{\circ} \mathrm{C}$ is supposed to be eutectic reaction of $\mathrm{Al}-\mathrm{Mg}$ and followed by highest peak at $640^{\circ} \mathrm{C}$ and supposed to correspond to eutectic reaction of $\mathrm{Al}-\mathrm{Zn}$. According to $\mathrm{Zn}$ content in this alloy powder for $5.5 \mathrm{wt} \%$, it is expected to have higher melting point based on $\mathrm{Al}-\mathrm{Zn}$ phase diagram where approximately $640^{\circ} \mathrm{C}$ is a minimum temperature to have liquid phase of Al$5.5 \mathrm{Zn}$. Eutectic reaction of $\mathrm{Al}-\mathrm{Cu}$ was expected in the trace at $540^{\circ} \mathrm{C}$, but the graph shows this with little appearance, due to small amount of $\mathrm{Cu}$ on this powder for $0.5 \mathrm{wt} \%$. From DSC curves, sintering conditions can be estimated, as sintering temperature is expected at $0.6-0.75$ from melting point to be able to have strong bond between particles.

At TGA graph (black line), it seems mass of powder decreased starting from 300 to $350^{\circ} \mathrm{C}$ and increased little more starting from $450^{\circ} \mathrm{C}$ to $550^{\circ} \mathrm{C}$. The first declining line is supposed to remove lubricant from powder, as this powder content lubricant for $1.5 \mathrm{wt} \%$, and from the line it is completely reduced for $1.5 \mathrm{wt} \%$ at $350^{\circ} \mathrm{C}$. Adding lubricant into powder is to ease ejection force during compaction and to increase cohesive behavior between particles which supports diffusivity during sintering. But lubricant should be removed thoroughly before reaching sintering temperature. And $400^{\circ} \mathrm{C}$ seems to be safe temperature to completely reduce lubricant from powder. Gaining mass from 450 to $550^{\circ} \mathrm{C}$ seems to be resulting from reaction between aluminium oxide and magnesium and corresponding to DSC line at $450^{\circ} \mathrm{C}$ which is supposed to be eutectic point of Al-Mg. And another reason for gaining mass during these temperatures is reaction between aluminium and nitrogen gas to form aluminium nitride (AlN). But detection of aluminium nitride is still questionable due to lacking of proves by X-ray diffraction from sintered aluminium alloy which used nitrogen gas as atmosphere.

3.2. Sintering Behavior. Sintering is a process to bond compacted particles by using thermal force below melting point to be able to produce high dense materials. Sintering of this powder was carried out at $560^{\circ} \mathrm{C}-585^{\circ} \mathrm{C}$ for 1 hour. And atmosphere for sintering was ultra high purity nitrogen gas, because it has been proved that nitrogen gas supports densification process during sintering by reducing the pressure inside the pores which leads to pore filling mechanism [1]. Sintering density was measured to observe the densification behaviour as shown by Figure 3(a). It is expected that sintering density increased with increasing sintering temperature and it seems that optimum density was obtained at $580^{\circ} \mathrm{C}$ sintering temperature by reaching $96 \%$ relative density. At $585^{\circ} \mathrm{C}$, sintering density decreased because of abundance of liquid phase and grain growth which leads to particle agglomeration and formed porosity. This phenomenon is called Oswald ripening [6].

Compaction pressure has some effects on sintering properties of metal powder, because it supports having better interparticle bonding during sintering. To be able to produce high dense materials, using high compaction is suggested prior to sintering. That is the main reason that this research used high compaction pressure for $700 \mathrm{MPa}$. And the advantage of using high compaction pressure is the fact that surface of the sintered materials appears to be fully densified, so finishing process after sintering is not necessary. According to Figure 4(a) pores still remain at body center of samples, and this is related to liquid phase and uncompleted pore filling process during sintering. For highly compacted powder, interparticle bonding reaction could be done at lower temperature due to strong surface energy which leads to easy reaction between each particle, as shown by the graph, and Alumix 431D has high sintering density at $580^{\circ} \mathrm{C}$. Lower compaction pressure will need higher sintering temperature with lower sintering density as proved by Martín and Castro. They showed Alumix 431 powder has optimum sintering temperature at $610^{\circ} \mathrm{C}$ reaching only $94.9 \%$ relative sintering density using $400 \mathrm{MPa}$ as compaction pressure [4]. The disadvantage of using high compaction pressure is reducing wearability of mold and needing more power during compaction process even if it will give clean-porosity surface.

Hardness of sintered Alumix 431D was investigated to measure how sintering density corresponded to mechanical properties. Figure 3(b) shows highest hardness was obtained at same optimum sintering temperature of $40 \mathrm{HRB}$. This shows that porosity plays important role in mechanical properties of sintered aluminium as porosity tends to reduce resistance of sintered aluminium to deformation.

Microstructure of sintered sample is shown in Figure 4(a), and it shows there are sintering precipitates inside the grains and at grain boundaries shown by white color. SEM picture shows quite high densification level with lower rate of pore. Elemental analysis was performed by EDS to determine chemical compositions on selected locations as shown in Figure 4(b). Figure 5 shows the element distributions from some locations as obtained by EDS analysis. The point analysis clearly shows differences in chemical compositions in locations numbered from 1 to 4 as shown in Table 1. This indicates reaction and diffusion during sintering in liquid state. Locations number 1 and number 2 seem to be $\alpha$ aluminium and locations number 3 and number 4 are intermetallic phases. Location number 3 contains high amount 


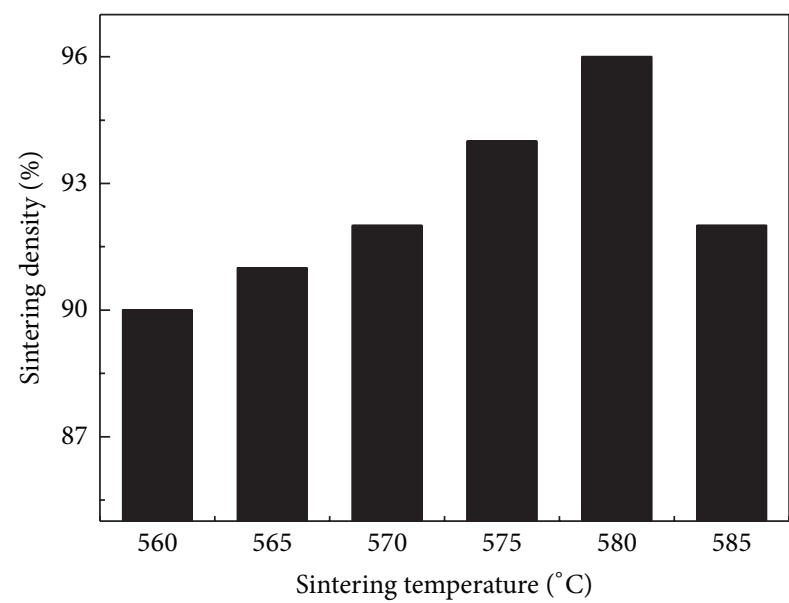

(a)

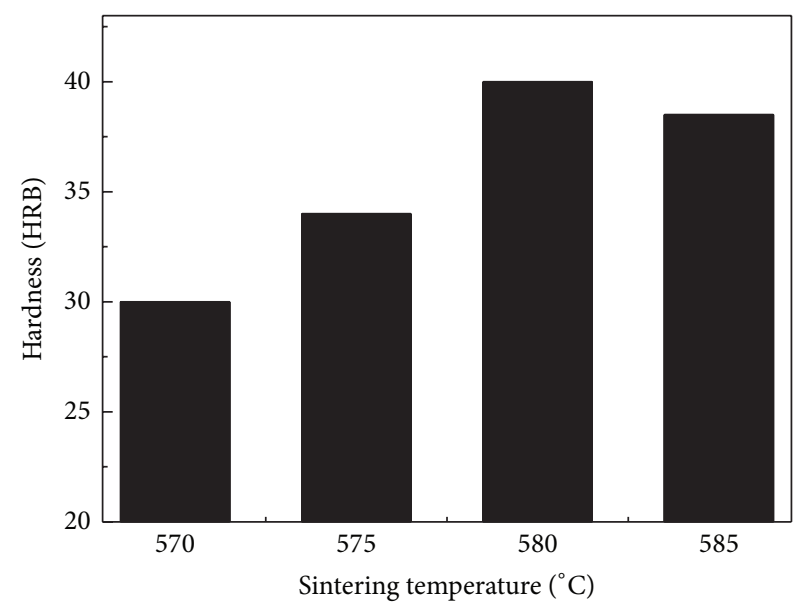

(b)

FIGURE 3: (a) Sintering density and (b) HRB hardness as a function of sintering temperature for Alumix $431 \mathrm{D}$ powder, and it seems that $580^{\circ} \mathrm{C}$ is an optimum sintering temperature.

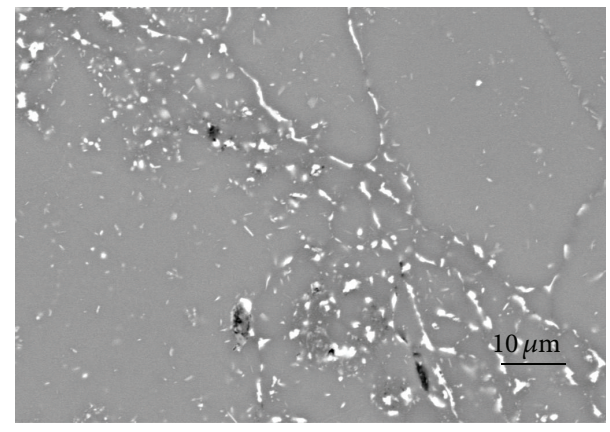

(a)

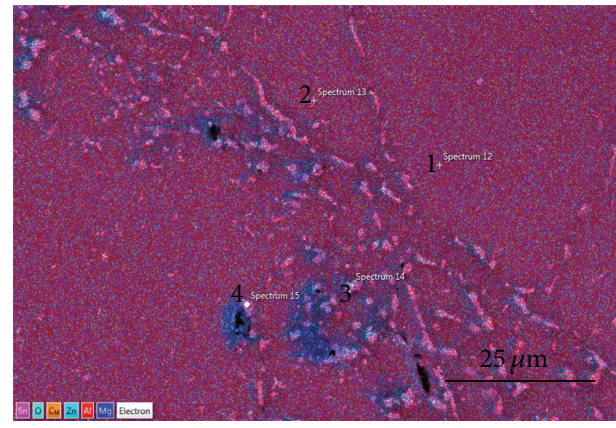

(b)

FIGURE 4: (a) SEM image of sintered Alumix 431D and (b) selected area and location for mapping and point elemental analysis of sintered Alumix 431D by EDS numbered from 1 to 4 .

TABLE 1: Elemental analysis from selected location in Figure 4(b) of sintered Alumix 431D.

\begin{tabular}{lccccccc}
\hline Number & $\begin{array}{c}\mathrm{Al} \\
(\mathrm{wt} \%)\end{array}$ & $\begin{array}{c}\mathrm{Zn} \\
(\mathrm{wt} \%)\end{array}$ & $\begin{array}{c}\mathrm{Mg} \\
(\mathrm{wt} \%)\end{array}$ & $\begin{array}{c}\mathrm{Cu} \\
(\mathrm{wt} \%)\end{array}$ & $\begin{array}{c}\mathrm{Sn} \\
(\mathrm{wt} \%)\end{array}$ & $\begin{array}{c}\mathrm{O} \\
(\mathrm{wt} \%)\end{array}$ & $\begin{array}{c}\mathrm{Si} \\
(\mathrm{wt} \%)\end{array}$ \\
\hline 1 & 62.76 & 4.81 & 1.5 & 0.89 & - & 0.32 & - \\
2 & 61.8 & 5.33 & 1.47 & 1.13 & - & 0.31 & - \\
3 & 48.97 & 12.56 & 5.52 & 5.39 & - & 2.09 & - \\
4 & 48.54 & 4.71 & 4.39 & 1.27 & 6.72 & 6.96 & 0.73 \\
\hline
\end{tabular}

of zinc, and it is related to some intermetallic phase such as $\mathrm{MgZn}_{2}$. And number 4 shows tin as an impurity and high amount of magnesium, which is related to formation of spinel $\mathrm{MgAl}_{2} \mathrm{O}_{4}$ as a result from reaction between magnesium and oxide layer on aluminium particles as follows:

$$
3 \mathrm{Mg}+4 \mathrm{Al}_{2} \mathrm{O}_{3} \longrightarrow 3 \mathrm{MgAl}_{2} \mathrm{O}_{4}+2 \mathrm{Al}
$$

This reaction results in decomposition of magnesium on grain boundary or close to pore, so it is expected to see some magnesium in grain boundary. Magnesium behavior during sintering was investigated by several researchers. Pieczonka et al. showed that magnesium moves to surface of aluminium particles at temperature of $450^{\circ} \mathrm{C}$ by dilatometry measurement [7]. And Lumley et al. investigated the effect of magnesium content on oxide layer removal from aluminium particles, and they showed that $0.5 \mathrm{wt} \%$ of magnesium is enough to remove oxide layer during sintering [8]. This reaction between magnesium and oxide layer is usually below sintering temperature. Point number 15 shows that there is tin, and it seems to be an impurity coming from this alloy powder.

To investigate intermetallic phases during sintering, $\mathrm{X}$ ray diffraction was carried out as shown in Figure 6. Aluminium is dominant peak in the XRD spectrum followed by intermetallic $\mathrm{MgZn}_{2}$ and $\mathrm{CuAl}_{2}$ phases. $\mathrm{MgZn}_{2}$ is a precipitate which is expected to be formed during sintering due to possibility of formation of GP zones, $\eta^{\prime}$ and $\eta$, even though this phase is coherent with $\alpha$ aluminium. $\mathrm{CuAl}_{2}$ is precipitate which is commonly found in $\mathrm{Al}-\mathrm{Cu}$ alloy and easily formed at room temperature at certain amount of $\mathrm{Cu}$. And there is unknown phase on XRD peak pattern, and it 


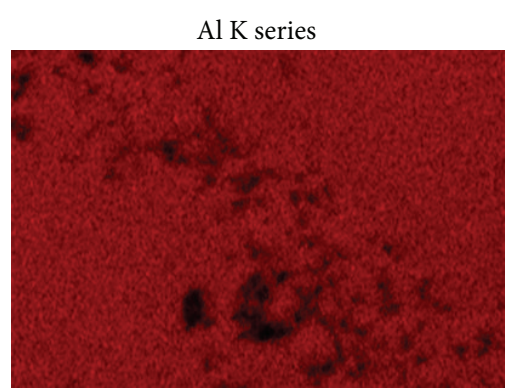

$25 \mu \mathrm{m}$

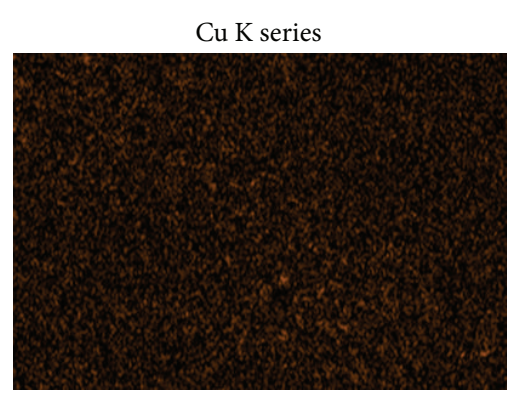

$25 \mu \mathrm{m}$

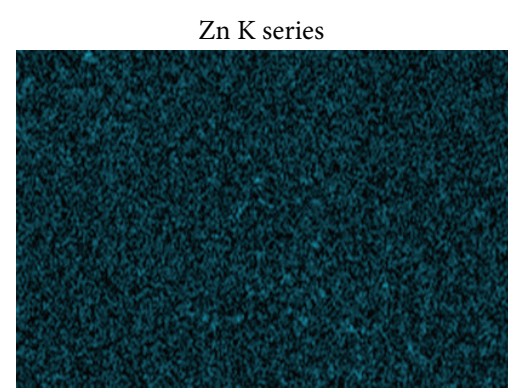

$25 \mu \mathrm{m}$

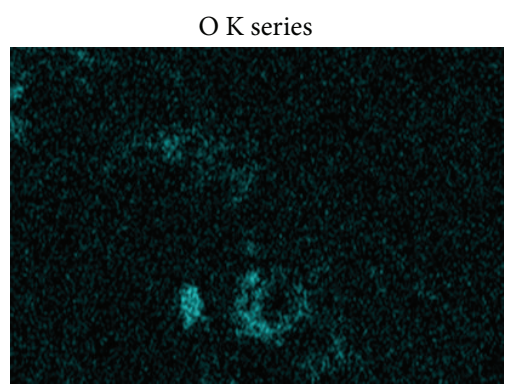

$25 \mu \mathrm{m}$

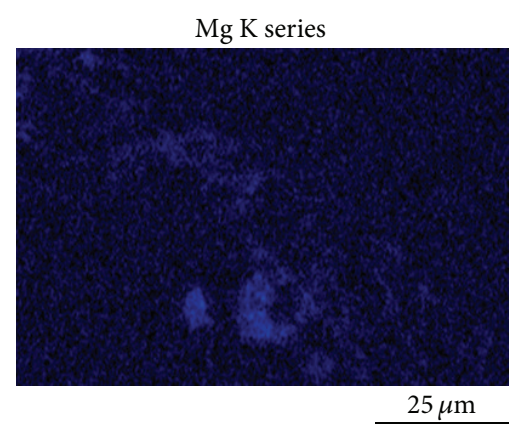

Sn K series

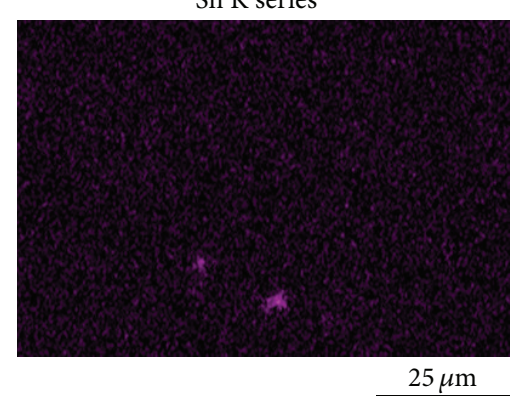

FIGURE 5: Elemental distribution analysis by EDS of sintered Alumix 431D starting with Al, Zn, and Cu which homogenously dispersed throughout the surface and $\mathrm{Mg}, \mathrm{O}$, and $\mathrm{Sn}$ seem to be concentrated at certain places on the surface.

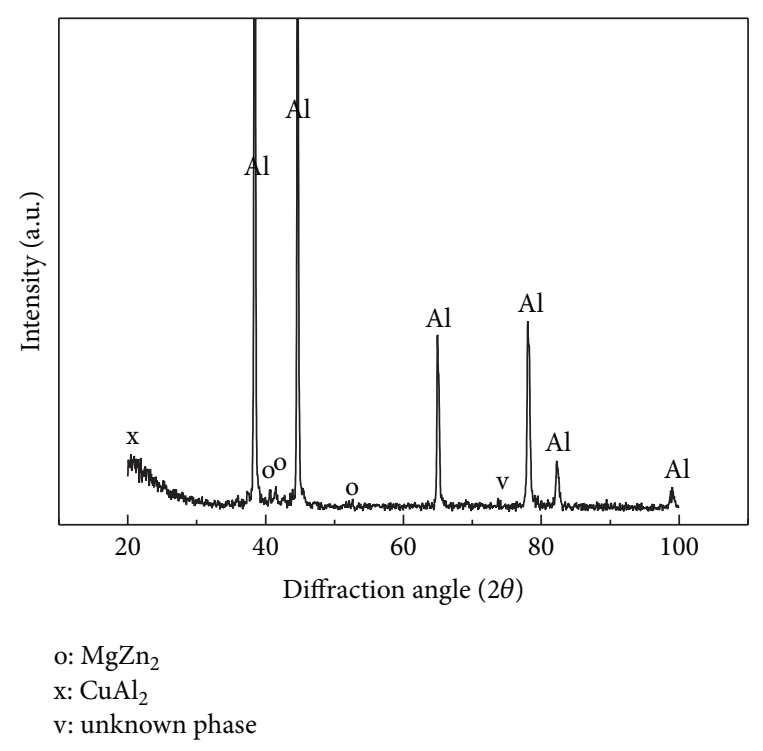

FIGURE 6: X-ray diffraction pattern of sintered Alumix 431D powder.

seems to be the responsibility of tin which was found on EDS point analysis.

3.3. T6 Heat Treatment. The T6 heat treatment is usually done to aluminium alloys to optimize their mechanical properties. The investigated powder has similar alloy system to $7 \mathrm{XXX}(\mathrm{Al}-\mathrm{Zn}-\mathrm{Mg}-\mathrm{Cu})$ alloy. These materials are heat treatable and they possess a potential to form strengthening precipitates such as $\mathrm{MgZn}_{2}$ and $\mathrm{CuAl}_{2}$. These strengthening precipitates will form after reaching optimum aging conditions and have been solutionized and water quenched before. Figure 7(a) shows hardness of the sintered samples after T6 heat treatment as a function of sintering temperature. As expected, hardness of $68 \mathrm{HRB}$ was achieved as the highest hardness and obtained after being sintered at $580^{\circ} \mathrm{C}$ sintering temperature followed by T6 heat treatment. And previously, this sintering condition also gave highest sintering density and hardness. Tensile strength load curves are showed in Figure 7(b), and there is an improvement in sample after T6 heat treatment by reaching the tensile strength $513 \mathrm{MPa}$ with $5 \%$ elongation. The improvement of tensile strength after T6 heat treatment is related to strengthening precipitates which impede dislocation movement during tensile deformation and, as a result, tensile strength increased. Strengthening precipitates which were formed during $\mathrm{T} 6$ heat treatment were investigated by XRD as shown by Figure $8 . \mathrm{MgZn}_{2}$ was found to be dominant strengthening precipitates in this powder followed by $\mathrm{CuAl}_{2}$. The process of these precipitates formation is as follows:

Supersaturated solid solution

$$
\longrightarrow \text { Guinier-Preston Zones }(\mathrm{GPZ}) \longrightarrow \eta^{\prime} \longrightarrow \eta\left(\mathrm{MgZn}_{2}\right)
$$

Hexagonal close-packed (HCP) crystal structure of $\mathrm{MgZn}_{2} \eta$ phase formed after increasing time of $\eta^{\prime}$ phase to arrange into the incoherent equilibrium phase. This $\eta$ phase is the obstacle dislocation movement, and as a result increasing mechanical properties are observed [9-11].

SEM supplemented by EDS microanalyses was performed to observe microstructures after T6 heat treatment 


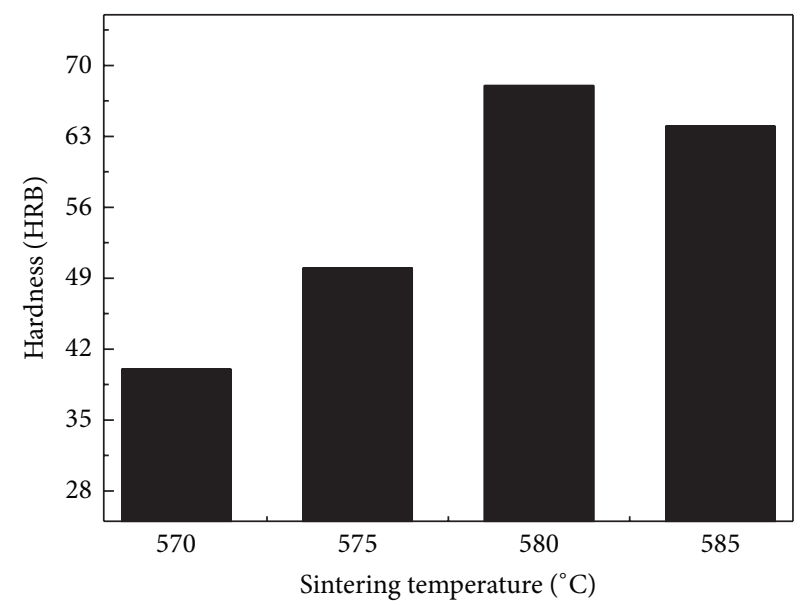

(a)

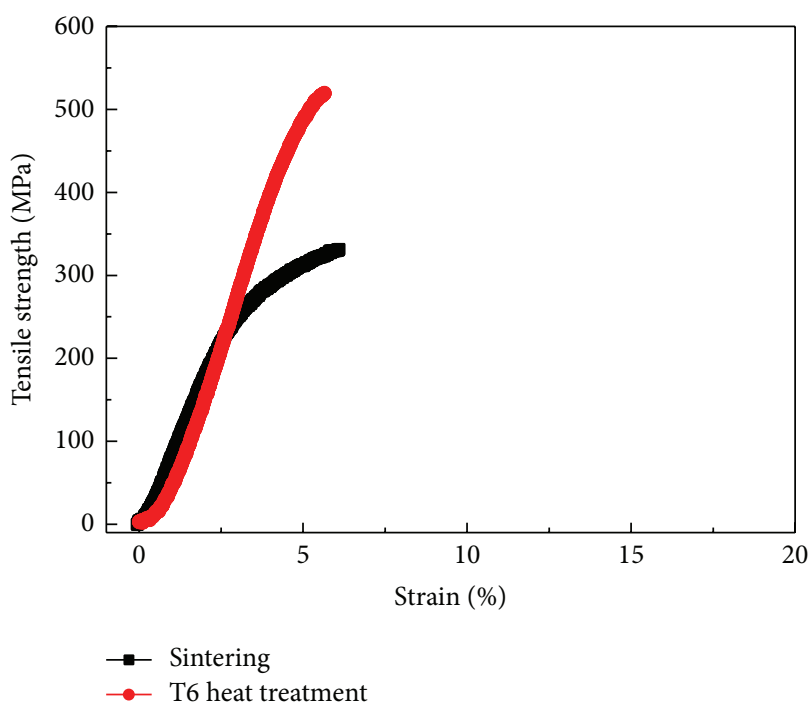

(b)

Figure 7: (a) Hardness and (b) stress-strain curve at tensile test of Alumix 431D before and after T6 heat treatment (for $580^{\circ} \mathrm{C}$ sintering temperature).

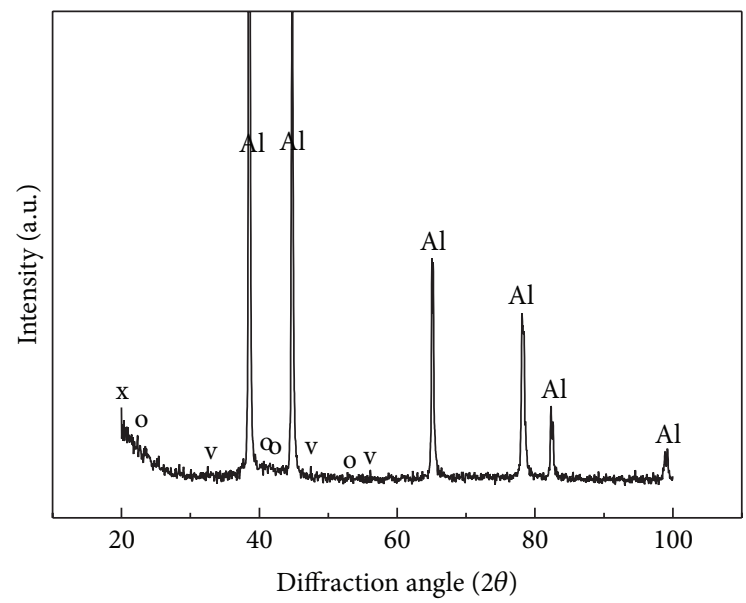

o: $\mathrm{MgZn}_{2}$

$\mathrm{x}: \mathrm{CuAl}_{2}$

v: unknown phase

FIgURE 8: X-ray diffraction pattern of Alumix 431D after T6 heat treatment.

as shown in Figures 9(a) and 9(b). Compared to sintered samples (as shown in Figure 3(a)), Figure 9(a) shows that some intermetallic phases represented by white colour seem to dissolve in aluminium during T6 heat treatment. Elemental analysis (shown in Figures 9(b) and 10) showed that aluminium, zinc, and copper are homogenously dispersed throughout the sample as well as shown by sintered samples without T6 treatment. And in addition, high concentration of magnesium is still located at grain boundaries as well as sample after sintering (Figure 3(b)), and this might be related to the strengthening precipitate $\mathrm{MgZn}_{2}$ and the oxide layer as oxygen content is still near the grain boundary. There are
TABLE 2: Elemental analysis of Alumix 431D after T6 heat treatment from Figure 9(b).

\begin{tabular}{lccccc}
\hline Number & $\begin{array}{c}\mathrm{Al} \\
(\mathrm{wt} \%)\end{array}$ & $\begin{array}{c}\mathrm{Zn} \\
(\mathrm{wt} \%)\end{array}$ & $\begin{array}{c}\mathrm{Mg} \\
(\mathrm{wt} \%)\end{array}$ & $\begin{array}{c}\mathrm{Cu} \\
(\mathrm{wt} \%)\end{array}$ & $\begin{array}{c}\mathrm{O} \\
(\mathrm{wt} \%)\end{array}$ \\
\hline 1 & 79.65 & 5.54 & 1.82 & 1.57 & 0.35 \\
2 & 78.96 & 5.88 & 1.91 & 1.74 & 0.34 \\
3 & 76.66 & 5.81 & 2.42 & 1.83 & 0.85 \\
4 & 78.1 & 5.68 & 1.88 & 1.69 & 0.32 \\
5 & 78.25 & 5.76 & 1.9 & 1.74 & 0.32 \\
\hline
\end{tabular}

unknown phases on XRD peak pattern in Figure 8, and, based on EDS elemental analysis, there are two different elements which are iron and tin. These elements are not subjects of chemical constitution in this aluminium alloy, so they are impurities. And they are responsible for unknown phase on XRD graph. Table 2 shows different chemical composition on selected point analysis by EDS, and it seems that chemical compositions of T6 heat treated sample have been homogenized as shown by their similar data representing elements distribution and chemical compositions in selected locations.

\section{Conclusions}

High compactability and sinterability by reaching high green density and sintering density were proved for Alumix 431D powder. With high compaction pressure of $700 \mathrm{MPa}$, sintering density of Alumix 431D reached optimum sintering density at $96 \%$ relation to theoretical one. Microstructures showed high densification especially on surface which is expected to reduce finishing work after sintering process, but pores still remain inside the sintered materials due to incomplete pore filling mechanism during sintering. 


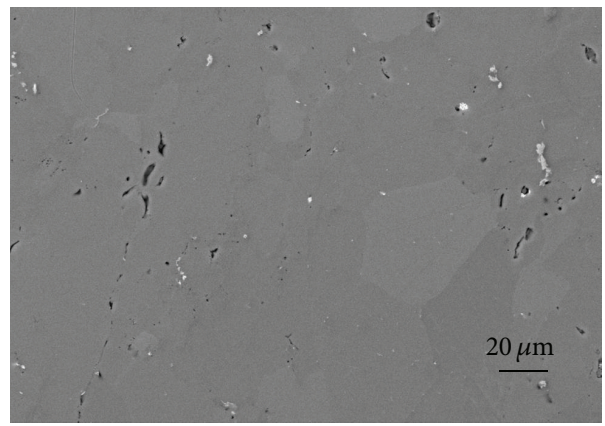

(a)

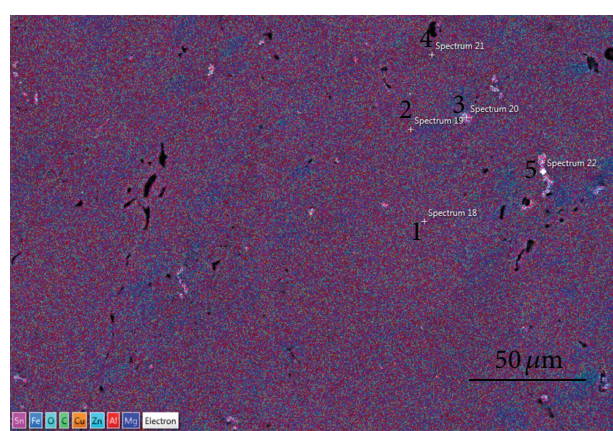

(b)

FIGURE 9: (a) SEM image of Alumix 431D after T6 heat treatment and (b) selected area and locations for mapping and point elemental analysis by EDS numbered 1-5.

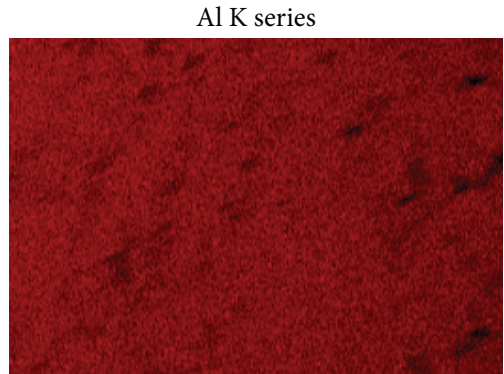

$25 \mu \mathrm{m}$

$\mathrm{Cu}$ K series

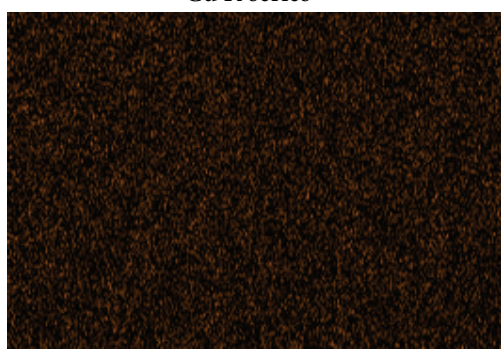

$25 \mu \mathrm{m}$

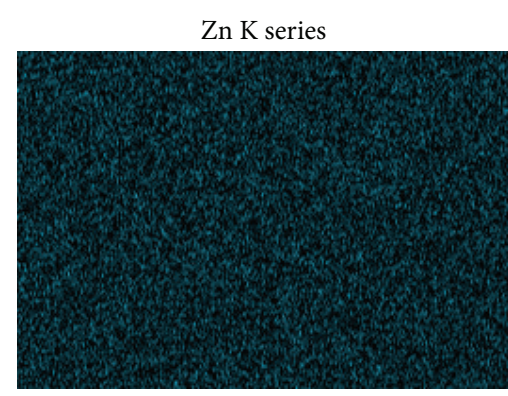

$25 \mu \mathrm{m}$

O K series

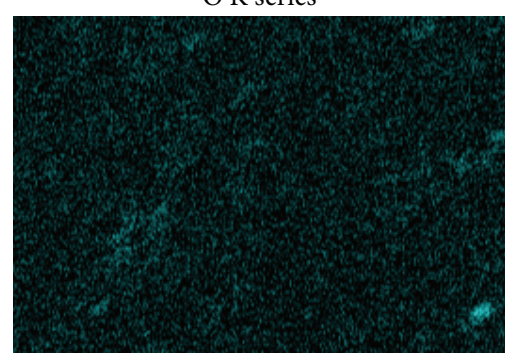

$25 \mu \mathrm{m}$
Mg K series

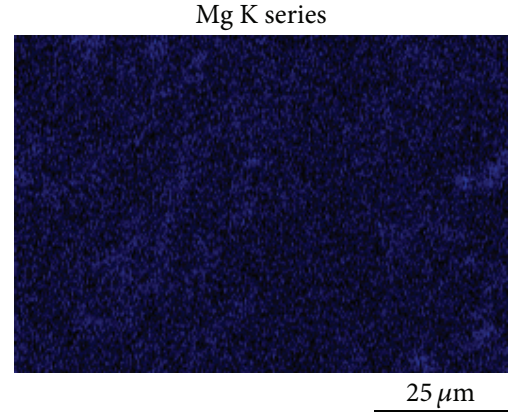

Sn K series

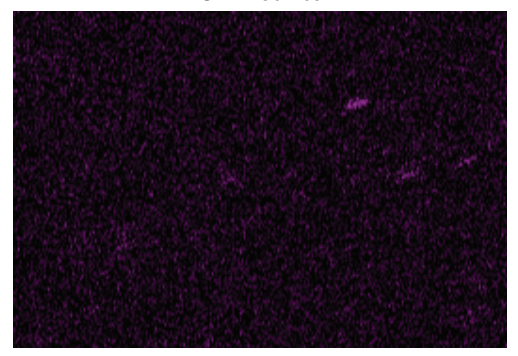

$25 \mu \mathrm{m}$

Fe K series

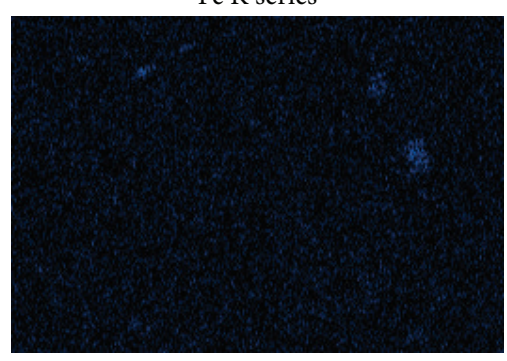

$25 \mu \mathrm{m}$

Figure 10: Elemental distribution analysis by EDS of Alumix 431D after T6 heat treatment starting with Al, Zn, and Cu which homogenously dispersed throughout the surface and $\mathrm{Mg}, \mathrm{O}, \mathrm{Fe}$, and $\mathrm{Sn}$ seem to be concentrated at certain places on the surface.

Obtained mechanical properties confirmed microstructural and phase analyses. At optimum sintering conditions, that is, at $580^{\circ} \mathrm{C}$, the Alumix $431 \mathrm{D}$ showed the highest hardness and tensile strength reaching up to $40 \mathrm{HRB}$ and $329 \mathrm{Mpa}$ for sintered materials and $68 \mathrm{HRB}$ for sintered materials after
T6 heat treatment. This means strengthening precipitates from this powder were successfully formed during T6 heat treatment process by increasing their mechanical properties as it has been confirmed by X-ray diffraction showing $\mathrm{MgZn}_{2}$ and $\mathrm{CuAl}_{2}$ as strengthening precipitates. 


\section{Conflict of Interests}

The authors declare that there is no conflict of interests regarding the publication of this paper.

\section{Acknowledgments}

This research is supported by Fundamental R\&D Program for Core Technology of Materials funded by the Ministry of Knowledge and Economics, Republic of Korea. Support of the project NETME Centre PLUS (LO1202) funded by Ministry of Education, Youth and Sport and Czech Science Foundation under Project no. 13-35890S is further acknowledged.

\section{References}

[1] G. B. Schaffer, B. J. Hall, S. J. Bonner, S. H. Huo, and T. B. Sercombe, "The effect of the atmosphere and the role of pore filling on the sintering of aluminium," Acta Materialia, vol. 54, no. 1, pp. 131-138, 2006.

[2] H. Rudianto, S. Yang, K.-W. Nam, and Y.-J. Kim, "Mechanical properties of Al-14Si-2.5Cu-0.5Mg aluminum-silicon P/M alloy," Reviews on Advanced Materials Science, vol. 28, no. 2, pp. 145-149, 2011.

[3] F. V. Lenel, Powder Metallurgy Principles and Application, Metal Powder Industries Federation (MPIF), Princeton, NJ, USA, 1960.

[4] J. M. Martín and F. Castro, "Liquid phase sintering of P/M aluminium alloys: effect of processing conditions," Journal of Materials Processing Technology, vol. 143-144, no. 1, pp. 814-821, 2003.

[5] Z. Y. Liu, T. B. Sercombe, and G. B. Schaffer, "The effect of particle shape on the sintering of aluminum," Metallurgical and Materials Transactions A: Physical Metallurgy and Materials Science, vol. 38, no. 6, pp. 1351-1357, 2007.

[6] D. W. Heard, I. W. Donaldson, and D. P. Bishop, "Metallurgical assessment of a hypereutectic aluminum-silicon P/M alloy," Journal of Materials Processing Technology, vol. 209, no. 18-19, pp. 5902-5911, 2009.

[7] T. Pieczonka, T. Schubert, S. Baunack, and B. Kieback, "Dimensional behaviour of aluminium sintered in different atmospheres," Materials Science and Engineering A, vol. 478, no. 1-2, pp. 251-256, 2008.

[8] R. N. Lumley, T. B. Sercombe, and G. B. Schaffer, "Surface oxide and the role of magnesium during the sintering of aluminum," Metallurgical and Materials Transactions A: Physical Metallurgy and Materials Science, vol. 30, no. 2, pp. 457-463, 1999.

[9] N. Q. Chinh, J. Lendvai, D. H. Ping, and K. Hono, “The effect of $\mathrm{Cu}$ on mechanical and precipitation properties of $\mathrm{Al}-\mathrm{Zn}-\mathrm{Mg}$ alloys," Journal of Alloys and Compounds, vol. 378, no. 1-2, pp. 52-60, 2004.

[10] K. Stiller, P. J. Warren, V. Hansen, J. Angenete, and J. Gjønnes, "Investigation of precipitation in an $\mathrm{Al}-\mathrm{Zn}-\mathrm{Mg}$ alloy after twostep ageing treatment at $100^{\circ} \mathrm{C}$ and $150^{\circ} \mathrm{C}$," Materials Science and Engineering A, vol. 270, no. 1, pp. 55-63, 1999.

[11] L. Hadjadj, R. Amira, D. Hamana, and A. Mosbah, "Characterization of precipitation and phase transformations in $\mathrm{Al}-\mathrm{Zn}$ $\mathrm{Mg}$ alloy by the differential dilatometry," Journal of Alloys and Compounds, vol. 462, no. 1-2, pp. 279-283, 2008. 

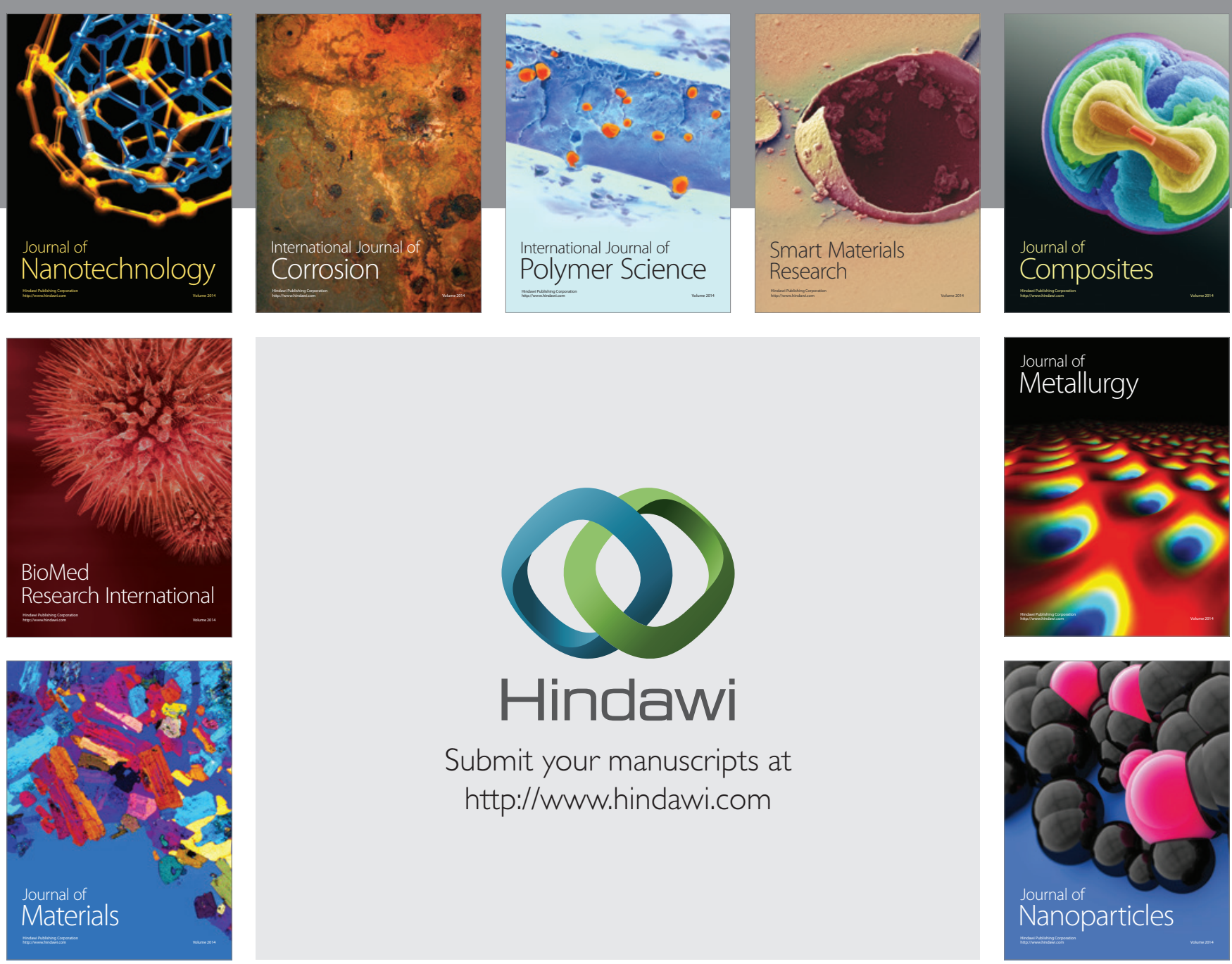

Submit your manuscripts at http://www.hindawi.com
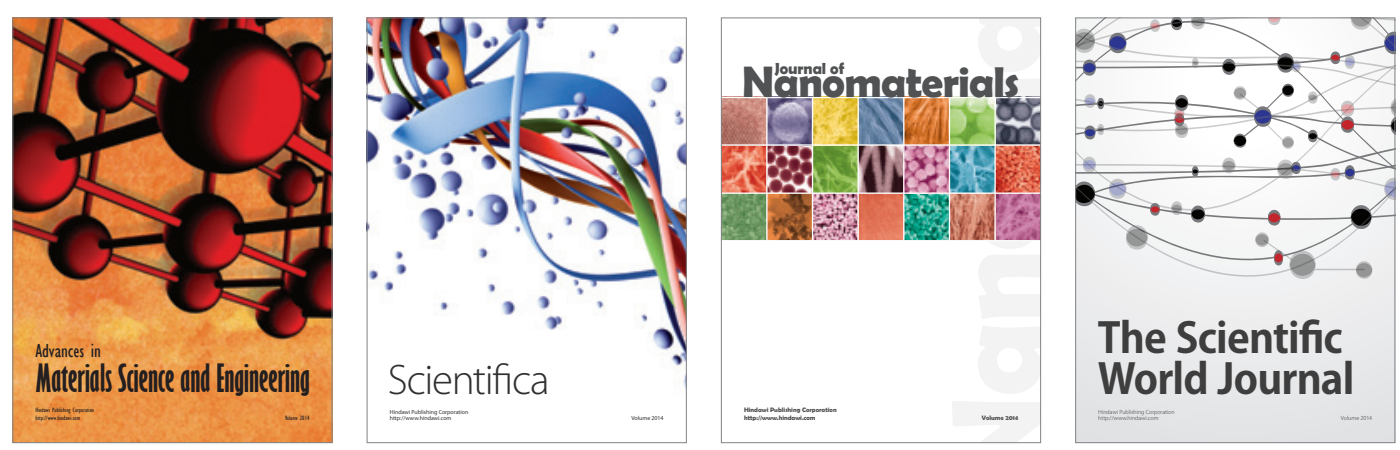

\section{The Scientific World Journal}
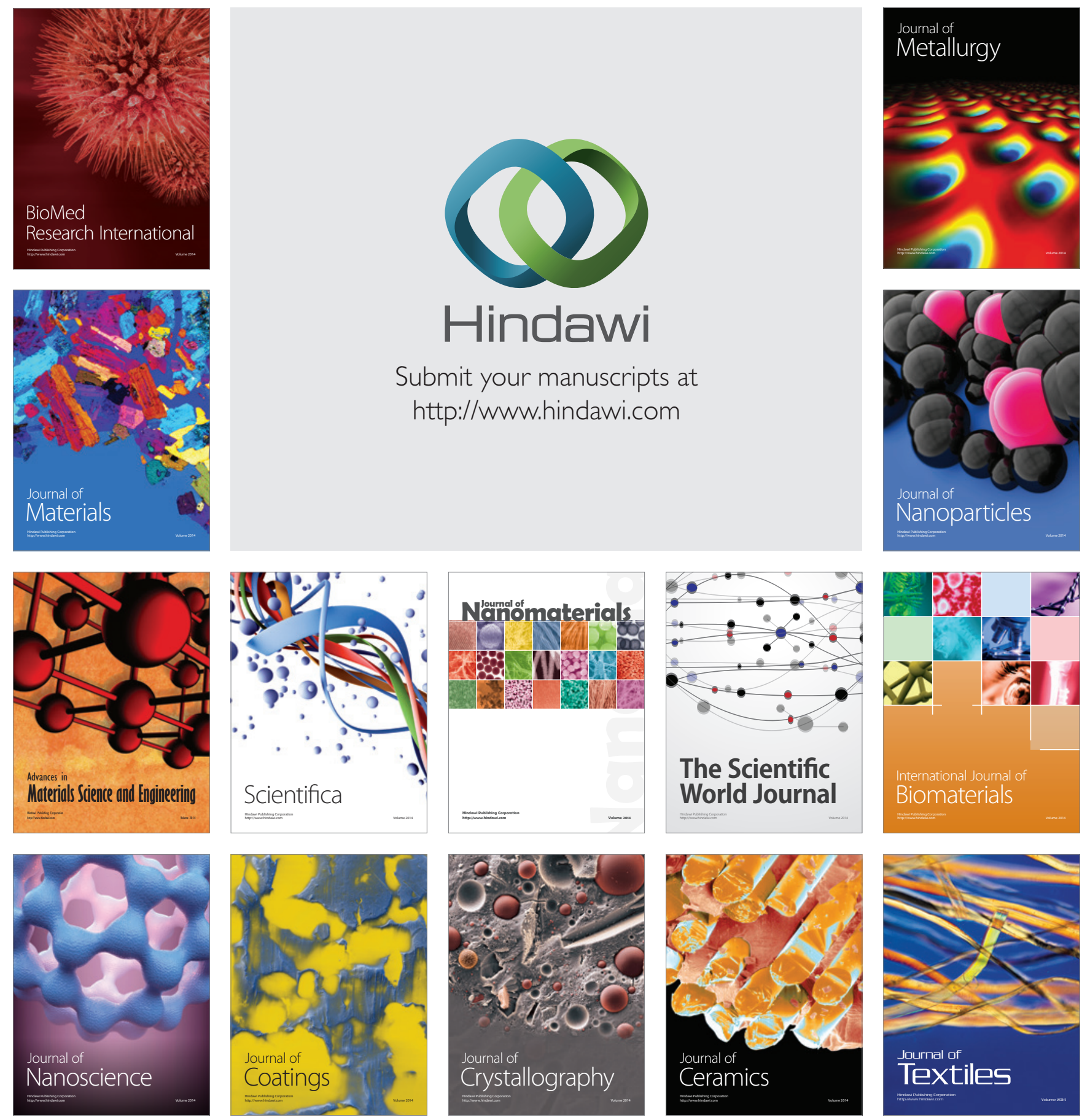